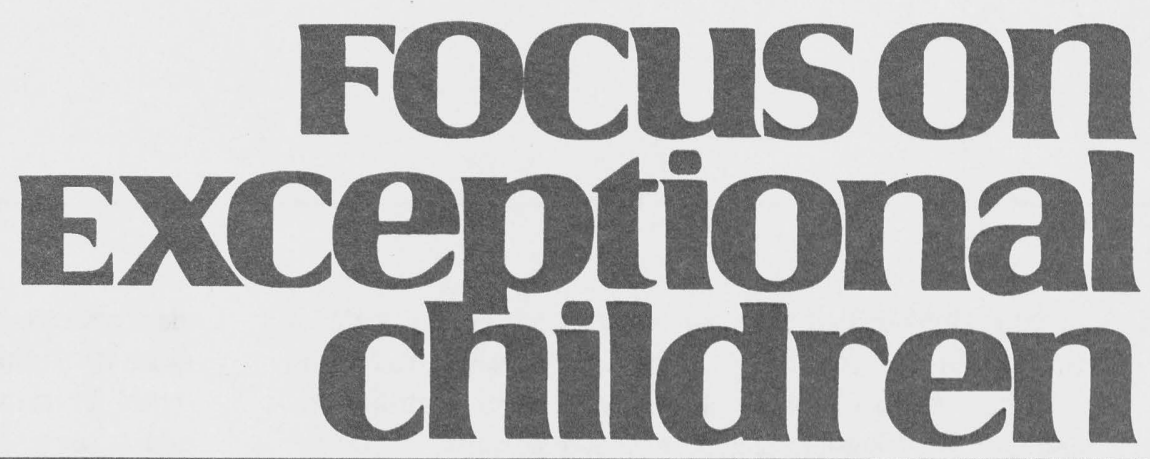

\title{
Teaching Writing Strategies and \\ Self-Regulation Procedures To Middle School Students with Learning Disabilities
}

\author{
Susan De La Paz
}

In 1992, the U.S. Department of Education awarded a major grant to the National Council of Teachers of English (NCTE) and the International Reading Association (IRA) to define content standards for the English language arts, grades $\mathrm{K}-12$. After more than 3 years and the involvement of thousands of contributors (including teachers, parents, administrators, researchers, and policy analysts), a set of 12 standards was established, defining what the IRA and NCTE believe students should know and be able to do with language by the time they complete their secondary schooling (NCTE/IRA, 1996). These standards, though listed as a set of 12 interrelated ideas, can be subgrouped into areas of understanding (via reading and appreciating text from a variety of cultures, ethnic groups, and so on), language use (including spoken, written, and "visual" language), conducting research (to pose and answer problems via a variety of informational sources), and lifelong learning (as a member of a literate community and for individually set purposes).

Three of the English content standards relate directly to written language proficiency, although each was written more broadly to include other forms of language use as well.

1. Students are expected to communicate effectively for a variety of audiences and purposes (Standard 4).

2. Students are expected to use different writing process elements strategically (Standard 5).

3. Students are expected to apply knowledge of structure, conventions, genre, and so on to create and analyze texts (Standard 6).

Thus, competent writers "are sensitive to the needs of different audiences and to the ways in which the purpose of a communication shapes the kind of ideas and information they choose and the way in which they present them" (NCTE/IRA, 1996, p.34). Moreover, proficient writers have learned to "vary their organizational strategy" depending on whether they are explaining something, arguing, persuading, or telling a story. Students are expected to learn more than individual elements of the writing process, as they should use writing techniques flexibly, knowing when to proceed methodically and when to adopt alternative strategies. Finally, students are charged with having a working knowledge of

Susan De La Paz is affiliated with Vanderbilt University. Funds from Vanderbilt University's Research Council made a portion of this article possible. 
accepted English language conventions, including grammar, punctuation, and spelling, so readers understand the writing.

Despite the emergence of these and other high national standards for English language arts, the National Assessment of Educational Progress (NAEP) longitudinal data from 1984 to 1996 indicate that the overall writing achievement of American students seems to be declining, or, at best, remaining the same over time (Campbell, Voelkl, \& Donahue, 1997). In general, fourth and eighth grade students' writing has remained constant while eleventh grade students' average writing scores have diminished over the past decade. Further, the percentage of students who receive the highest ratings for "effective, coherent" writing remains quite low $(0 \%-2 \%)$ at each of the tested grade levels, and those writing "complete, sufficient" texts is only slightly higher (16\% of eighth graders and $31 \%$ of eleventh graders).

Although the majority of secondary students receive ratings of "beginning focused, clear writing" (66\% of eighth graders and $83 \%$ of eleventh graders), this rating indicates that if, for example, a given writing task involves persuading one's audience, students at this level are not able to provide a convincing argument. The NAEP longitudinal data

\section{Focuson
Exceptional children}

ISSN 0015-511X FOCUS ON EXCEPTIONAL CHILDREN (USPS 203-360) is published monthly except June, July, and August as a service to teachers, special educators, curriculum specialists, administrators, and those concerned with the special education of exceptional children. This publication is annotated and indexed by the ERIC Clearinghouse on Handicapped and Gifted children for publication in the monthly Current Index to Journals in Education (CIJE) and the quarterly index, Exceptional Children Education Resources (ECER). The full text of Focus on Exceptional Children is also available in the electronic versions of the Education Index. It is also available in microfilm from Xerox University Microfilms, Ann Arbor, MI. Subscription rates: Individual, $\$ 30$ per year; institutions, \$40 per year. Copyright (C) 1999, Love Publishing Company. All rights reserved. Reproduction in whole or part without written permission is prohibited. Printed in the United States of America. Periodicals postage is paid at Denver, Colorado. POSTMASTER: Send address changes to:

Love Publishing Company

Executive and Editorial Office

9101 E. Kenyon Ave., Suite 2200

Denver, Colorado 80237

Telephone (303) 221-7333

Edward L. Meyen

University of Kansas

\section{Glenn A. Vergason} Georgia State University

Richard J. Whelan

University of Kansas Medical Center

Stanley F. Love

Publisher
Thomas S. Love

Associate Editor also indicate that students at all three grades are writing more often than students did in the past, that teachers currently focus more on reacting to students' ideas and feelings and less on correcting mistakes, that computers are used more frequently at home and at school, and that at the higher grades, students are writing more for their own enjoyment outside of school (Campbell et al., 1997).

These data, though based on summaries of students' performance and responses to written questionnaires, clearly indicate that students' current level of writing proficiency cannot be attributed solely to a "teaching crisis" (c.f., Graham, 1982), limited opportunity to engage in writing, inadequate access to technology, and so on. In accordance, proponents of the new English content standards also react to these outcomes without blaming schools and teachers for "failing to fulfill their responsibilities." Rather than proposing that these outcomes mean fewer and fewer students are able to write well, they believe that the current state of affairs reflects a mismatch between students' achievements and educators' increased expectations for students' literacy. Thus, while students (including those in special education programs) are expected to reach higher levels of performance, teachers are counted upon to make it possible for all students to attain such high standards.

Given these charges and their students' current skill level, where are teachers to begin? One beginning seems to be the use of long-term, contextually relevant cognitive strategy instruction as a complement to content-area teaching (Pressley et al., 1995). This approach may be especially relevant for the following reasons.

First, current literacy expectations seem to be matched well with contemporary models of strategy use. With respect to writing, a good strategy user knows a variety of strategies for writing (e.g., brainstorming to generate content) and uses metacognitive knowledge to search for relationships between current tasks and those previously accomplished through strategic mediation (Pressley et al., 1995). Competent strategy users recognize when existing strategies are appropriate and when they should try new approaches that are potentially more effective.

Second, results from a comprehensive meta-analysis of 180 intervention studies in special education in a variety of academic content areas indicate that cognitive strategy instruction is an effective approach to teaching, especially when combined with direct instruction in related or prerequisite information (Swanson \& Hoskyn, 1998). When taken as a group, writing interventions that included strategy instruction produced effect sizes of .68 for researchers' experimental measures such as a composition's overall quality, coherence, and the like. Although this result is not as strong as the combination of strategy and direct instruction for other content areas such as reading (total effect size 
$=85$ ), writing outcomes do seem to be in the moderate effect-size range and are based on a smaller number of intervention studies.

Third, the authors of the current English content standards recognize the importance of both self-regulation and explicit instruction in the learning process for all students. Believing that all students can learn, and that students often need explicit instruction in particular aspects of writing, teachers are seen as vital agents who help students reflect upon and monitor their own learning. In fact, learning how to learn is viewed as the fundamental element in students' language arts education. These authors echo almost precisely the words of strategy instruction proponents, stating, "If students are conscious of the strategies they use, they are better able to recognize when a familiar strategy is not working, and they are more prepared to adapt or abandon one strategy in favor of more effective alternatives" (NCTE/IRA, 1996, p. 9).

Finally, professional writers, though often idiosyncratic and choosing any of several approaches to composing text, are typically quite strategic in their efforts. Pulitzer prize winner Richard Rhoades, for example, compares organizing his notes to the work of a general.

\begin{abstract}
A general needs to know what troops and weapons he commands and how they're deployed, but he also needs to develop a strategy for fighting battles and winning the war. The battles probably won't go as he plans, of course. If his strategy is sufficiently flexible, he'll be able to adapt it to circumstances and still come out victorious. (Rhoades, 1995, p. 81)
\end{abstract}

The underlying metaphor here seems to be that strategies can be used to figure out how to structure writing, and that plans must be adapted to meet an author's changing needs in his or her production of text. Fortunately, a growing body of research suggests that teaching writing strategies and selfregulation procedures helps elementary and secondary students develop more sophisticated approaches to writing and improves the quality of their compositions. One form of cognitive strategy instruction-self-regulated strategy development-is the focus of the remainder of this article and is presented next.

\section{DEVELOPMENT OF SELF-REGULATED STRATEGIES (SRSD)}

Harris and Graham and their colleagues (Graham, Harris, MacArthur, \& Schwartz, 1991; Harris \& Graham, 1996) developed an approach referred to as the self-regulated strategy development (SRSD) model. Their approach is similar in many ways to other forms of cognitive strategy instruction in that students learn task-specific strategies for composing, such as planning and revising, and this learning is scaffolded to help them master the use of the strategies (Deshler \& Schumaker, 1986; Englert, Raphael, Anderson et al., 1991; Schumaker \& Deschler, 1992; Wong, 1997; Wong, Butler, Ficzere, \& Kuperis, 1997). With SRSD, however, students also learn procedures for regulating use of the strategy, the task, and undesirable behaviors (such as the use of negative self-statements) that impede performance. Selfregulatory procedures typically include goal setting, selfinstructions, and self-monitoring. Thus, teachers typically model and help students identify verbal statements and physical actions to promote student mastery of the targeted writing process.

To date, more than 20 studies using SRSD to teach writing strategies have been conducted. These include a variety of planning and revising strategies including semantic webbing (MacArthur, Schwartz, Graham, Molloy, \& Harris, 1996); brainstorming (Harris \& Graham, 1985); using text structure to generate writing content (De La Paz \& Graham, 1997a; 1997b); goal setting (Graham, MacArthur, Schwartz \& Voth, 1992); revising using peer feedback (MacArthur, Schwartz, \& Graham, 1991); and revising for both mechanics and substance (Graham \& MacArthur, 1988; Graham, MacArthur, \& Schwartz, 1995). These strategies have proven effective in teaching students to self-regulate their performance, resulting in substantial improvements in four aspects of students' performance: quality of writing, knowledge of writing, approach to writing, and self-efficacy (Graham, Harris, \& Troia, 1998). In addition, SRSD procedures have been integrated successfully in classrooms using a process approach to writing (Danoff, Harris, \& Graham, 1993; MacArthur et al., 1996; Sexton, Harris \& Graham, 1998).

The SRSD approach to teaching incorporates several stages of instruction that take place over 2 or more weeks, on average, as teachers scaffold students' learning, as well as transfer responsibility for independent use of the target strategy. These stages are (Harris \& Graham, 1996):

1. Developing (or activating) students' background knowledge;

2. Discussing the target strategy to be learned and obtaining students' commitment for learning;

3. Teacher modeling strategy use and self-regulatory statements;

4. Mastery (memorization) of any strategy mnemonics or routines;

5. Collaborative practice, in which teachers support the students' use of strategy in large or small groups of students; and

6. Independent practice, when instructional cues are gradually faded. 
This article presents one SRSD advanced planning strategy for composing expository essays, and a metacognitive routine aimed at teaching students a sophisticated procedure for revising persuasive essays. Middle school students were involved in both interventions, and empirical research supports their effectiveness (De La Paz, in press-a; De La Paz, Swanson, \& Graham, 1998). Explicit steps for executing specific components of the writing process (e.g., using text structure knowledge to develop five-paragraph essays or comparing one's written text to one's intended meaning) are outlined in the present article. Teachers who use strategies and provide procedural support as described here will be giving students scaffolded assistance for planning, drafting, and revising essays, which in turn may help them become more confident and adept at the writing process.

Teaching self-regulatory procedures such as those in this article must also be part of a writing program that includes instruction in more than self-regulation. Students with learning disabilities need to learn language conventions, for example, and they need to use self-regulatory procedures flexibly, adapting or discarding them in favor of new approaches as the writing task or setting requirements change.

\section{THE NEED FOR PLANNING}

Planning, and the ability to manage the composing process are especially important skills for novice writers to learn. Researchers who have studied the composing abilities of professional writers (Flower \& Hayes, 1980) and of children with adequate learning abilities and outcomes (Scardamalia \& Bereiter, 1986) have routinely found profound differences between the two groups of writers. Mature adult writers generally view planning and composing as a recursive process that includes developing an initial set of goals or plans to guide the writing process. They revise or enhance these goals as the composing process continues; furthermore, adults coordinate additional strategies for generating, organizing, evaluating, and revising what they intend to accomplish (De La Paz \& Graham, 1997a). In addition to using a process approach to writing, adult writers regulate the writing process by allocating differing amounts of resources to a given task, monitoring performance (e.g., numbers of pages written or overall quality), and using metacognitive knowledge to search for relationships between one task and others that were accomplished previously (Pressley et al.,1995).

In contrast to the planning and composing methods of proficient adult writers, students who are novices spend little time planning before composing (Scardamalia \& Bereiter, 1986). Students typically do not generate written notes before planning, and written text appears to be generated using a knowledge-telling approach. Students generally view writing prompts, such as those for persuasive and expository essays, as questions to be answered, and students frequently tell what they know and feel about the topic without first establishing global plans (McCutchen, 1988; Scardamalia \& Bereiter, 1987) or attempting to evaluate or revise their emerging text. In addition, the writing of young and novice writers has been compared to their oral language, as their finished text appears similar in length to a verbal response to the topic (i.e., equivalent to a single conversational turn; Bereiter \& Scardamalia, 1982).

Students with learning disabilities typically have additional difficulties with written language production that further interfere with the writing process. First, these students make considerably more spelling, capitalization, and punctuation errors than their normally achieving peers (cf. Deno, Marston, \& Mirkin, 1982; Moran, 1981). They also make more errors in word usage (Anderson, 1982; Poplin, Gray, Larsen, Banikowski, \& Mehring, 1980). They generate shorter texts than their peers (Englert \& Raphael, 1988; Graham, 1990; Montague, Graves, \& Leavell, 1991; Newcomer, Barenbaum, \& Nodine, 1988; Wong, Wong, \& Blenkinsop, 1989); and they have less legible handwriting (Graham \& Weintraub, 1996). As a result, compositions of students with learning disabilities are often judged to be of poorer quality than the compositions written by peers who do not have learning difficulties (Graham \& Harris, 1989; Newcomer \& Barenbaum, 1991).

Second, compared to their normally achieving peers, students with learning disabilities seem to have less knowledge of the structure of expository writing, or frames (e.g., compare/contrast) that writers often use in retrieving and organizing ideas. Students with learning disabilities also are less successful in sustaining their thinking about topics when retrieving ideas from memory (Englert \& Raphael, 1988). Moreover, these students frequently fail to include critical elements such as the premise or conclusion of their essays, and they generate a considerable amount of irrelevant or nonfunctional information in their compositions (Graham, 1990).

\section{PLAN AND WRITE: A STRATEGY FOR PLANNING EXPOSITORY ESSAYS}

To help remedy some of these planning difficulties, I collaborated with several general and special education teachers over the past 3 years to develop an advanced planning strategy for middle school students with and without learning disabilities. The following instructional strategy, referred to here by its mnemonics PLAN and WRITE, has been used to teach middle school students with different levels of writing proficiency to plan and compose expository 
essays "on demand" for a statewide timed writing assessment. General education teachers provided instruction to all students with support from resource teachers. In an initial study (De La Paz, in press a), positive results were found for students with LD as well as low-, average- and high-achieving writers. Following instruction, students' papers routinely became longer and more complex and improved in quality. Both writing performance and students' approach to the writing task remained improved 1 month after completion of the study.

In our project, teachers found it best to introduce each SRSD instructional component in one or more days. The entire instructional period ranged from 12 to 16 class sessions, spanning approximately 1 month of instruction, 4 days per week. For teachers wishing to follow our program, the first lesson provides information about the purpose and description of the target strategy. Two days are devoted to activating students' background knowledge of basic essay parts, synonyms, and different types (both form and function) of sentences. Teachers individually review students' entry writing abilities and explain, during the fourth session, how they have evaluated students' work.

Following this session, teachers spend up to 2 days modeling the PLAN and WRITE composing strategy. Students then engage in collaborative practice for 4 to 5 days-first working as a class, and then working in small groups of two or three students to plan and compose two collaborative essays. We found that at least five class sessions are necessary for students to engage in independent practice so students are able to reach criterion performance. Finally, one or more class periods are needed for students to gain mastery and to assess students' knowledge of the planning strategy.

To provide information about the PLAN and WRITE planning strategy in more detail, the following account illustrates both the phases of instruction (italicized as they evolve in the following text) as well as the actual strategy (indicated with bold font). Therefore, on the first day of instruction, teachers provide a description of the planning and composition strategy to establish the purpose of instruction. This includes a discussion on how writers use planning strategies when they write and the benefits of using the planning strategies. Teachers help students realize the purpose of instruction and the goal of learning (to write proficient essays and do well on the state's seventh- and eighth-grade writing assessment). Teachers then introduce the writing strategy and the rationale for each step. The mnemonics PLAN and WRITE are used to help students remember the strategy steps, and they also remind students to plan before starting to write and to reflect on qualities of good writing while composing. Table 1 provides an overview of the essay planning steps.

\section{TABLE 1 \\ The Expository Planning Strategy}

Planning strategy: PLAN Instructions for each planning step:

1. Pay attention to the prompt

Read the prompt. Decide (a) what you are being asked to write about, and (b) how to develop your essay.

2. List main ideas

Brainstorm possible responses to the prompt (a). Decide on one topic, then brainstorm at least three main ideas for (b) the development of your essay.

3. Add supporting ideas Think of details, examples, and elaborations that support your main ideas.

4. Number your ideas Number major points in the order you will use them.

How to remember to keep planning while composing your essay: WRITE

5. Work from your plan to develop your thesis statement.*

6. Remember your goals.

7. Include transition words for each paragraph.*

8. Try to use different kinds of sentences.

9. Exciting, interesting, $\$ 100,000$ words.

${ }^{*}$ Note. See cue cards for ways to develop the introductory paragraph, and to see sample transition words and phrases. Brainstorm ideas using a brainstorming sheet or regular notebook paper. Write your essay on your essay sheet or lined paper. 
The primary focus of the first step, "Pay attention to the prompt," is to help students fully consider the topic by identifying (a) what they are being asked to write about and (b) how they should develop their essay. To illustrate, consider one prompt from a recent Tennessee state writing assessment: "Think of the most important invention of the last 100 years. Write an essay telling what invention you have selected, and give reasons explaining why it is the most important." Students are taught to underline once what they are being asked to write about (an important invention) and to underline twice how they are asked to develop it (reasons explaining why it is important).

Prompts vary in complexity, which reflects the variety (or inconsistency) in the state assessment. For example, in a previous year students encountered a different type of prompt: "Think about a special event you will never forget. Write an essay telling what happened, how you felt, and why it is unforgettable." To answer the second prompt, students identify a single event and develop the essay by explaining what happened, their emotions during or after the event, and why it was memorable.

During the second step, "List main ideas," the writer first decides on one topic (such as which invention or which event to write about), and then he or she brainstorms at least three main ideas for development of the essay (three reasons why the invention is important, or a specific memorable event, what happened, how he or she felt about it, and why it was remarkable).

In the third step, "Add supporting ideas," students add at least three details, examples, or elaborations that supported each main idea. Students are taught to return to the second step if they are not able to generate an adequate number of details in support of each main idea.

The fourth step, "Number your ideas," reminds students to arrange their main ideas in the order they plan to use them, and to arrange these ideas in a meaningful way (i.e., the most important reason why an invention is important could become the first or last body paragraph in the essay).

Students follow the steps identified by the second mnemonic, WRITE, to help them continue the planning process while composing, by focusing their attention on additional features of good writing.

The fifth step, "Work from your plan to develop your thesis statement," reminds students to incorporate ideas from their plan into a thesis statement. Within this step we developed a basic and more sophisticated approach for writing fiveparagraph essays. In the basic approach, the introductory paragraph provides an overview for content in the three body paragraphs, and a concluding paragraph restates the main ideas. "You tell them what you're going to tell them, you tell them, you tell them, you tell them, and you tell them what you told them you were going to tell them" summarizes this approach.
To meet the needs of more capable writers, an alternative strategy for writing more sophisticated introductory paragraphs is embedded in the planning strategy. Students are shown that, as an alternative to presenting their thesis statement as their first sentence, they can decide to "start with an attention getter," or lead up to their thesis statement in one of the following ways:

1. Use a series of questions or statements.

2. Use a brief or funny story.

3. Use a mean or angry statement.

4. Start with the opposite opinion from what you believe.

Cue cards (see Figure 1) list these alternatives, and, during instruction, teachers model for the students both ways to write introductory paragraphs. Thus, eighth-grade students are shown how to compose both basic and advanced introductory paragraphs, whereas seventh-grade students are shown the more advanced approach on an individual basis after demonstrating mastery with the basic approach to writing introductory paragraphs.

The sixth step, "Remember your goals," serves an additional reminder to continue planning as students compose. Teachers and students collaboratively set goals, as a class or in individual conferences. These goals (see below) reflect qualities of good writing and incorporate specific criteria from the Tennessee scoring rubric.

1. Address the topic (answer all parts of the prompt).

2. Remember to explain, clarify, inform, or instruct (write an expository essay).

3. Remain on topic-keep a "central focus."

4. Show clear organization with frequent transitions (connecting words).

5. Include clear supporting facts, examples, details, and definitions that illustrate your main points.

6. Explain your topic so your reader will know what you are writing about.

7. Use mature, specific vocabulary.

8. Use different kinds of sentences (simple, compound, complex, as well as declarative, imperative, exclamatory, and question) that vary in length.

9. Have few or no errors in grammar (for example, matching subjects and verbs).

10. Make your essay lively and engaging (fun to read).

As students near mastery of the target strategy, teachers help students refine their goals, focusing on one or two areas of continued need, based on the quality of essays written during independent practice.

The last three steps of the strategy give specific suggestions for on-line planning. Students are told to: "Include 
Introductory paragraph: Thesis statement first

- Answer the prompt in your first sentence.

- Write your first main idea as the second sentence.

- Write your second main idea as the third sentence.

- Write your third main idea as the last sentence.
Introductory paragraph: Thesis statement last

- "Start with an attention getter" and lead up to the thesis statement.

- Answer the prompt in your last sentence. Include your first, second, and third main idea in a series.

(2)

First body paragraph: Use transition words to introduce ideas

- First (of all) ...

- (The/My) first (reason/example) is . . .

- One (reason why/example is) ...

- To begin with . . .

- In the first step ...

- To explain ...
Second and third body paragraphs: Use transition words to connect or add ideas, or give examples

- Second... Third...

- My second (reason/example) is ...

- Furthermore...

- Another (reason) to support this is ...

- What is more. .

- The next step ..
(5)
(4)

Concluding paragraph: Use transition words to summarize ideas

- In conclusion/To conclude ...

- In summary/To sum up . . .

- As one can see . . . /As a result

- In short/All in all .. .

- It follows that...

- For these reasons...

Note. Italicized cards on different colored cardstock were provided for students who wished to attempt more sophisticated introductory paragraphs.

\section{FIGURE 1 \\ Cue cards for PLAN and WRITE strategy}

transition words for each paragraph," to "Try to use different kinds of sentences," and to include "Exciting, interesting, $\$ \mathbf{1 0 0 , 0 0 0}$ words" in their compositions. These suggestions are intended to serve as additional prompts to help students reflect on the state criteria for proficient essays. Our students also learn that if they are able to plan and compose their essays in less than the 35-minute time limit, they should verify whether they completed these last three steps accurately as they re-read their essays. Students are encouraged to check that they used transition words appropriately, to make minor changes, such as creating a compound sentence from adjacent simple sentences, and to substitute synonyms for words that occur more than once in their essay.

After describing the PLAN and WRITE strategy, teachers activate students' prior knowledge of the basic parts of an essay, how synonyms can be effective, and different types of sentences. To accomplish this objective, teachers present model essays written by prior students on successive days. They first show students a sample writing prompt, execute the first step of the planning strategy, and then engage the class in a discussion about the model essays. 
On the first day, students collaboratively read the essay and label the introductory, body, and concluding paragraphs. Then they examine whether the model essay contains a good thesis statement and identify transition words in the paragraphs. Students also search the essay for different types of sentence according to form (simple, compound, and complex) and function (declarative, imperative, exclamatory, and question). Students are encouraged to take notes throughout the class discussion, and their suggestions for revising the essay are noted on a projected copy of the model essay.

The second day is essentially a repetition of the first. The main difference is a focus on the writer's vocabulary rather than the different types of sentences. Students identify what they considered to be "exciting, interesting, $\$ 100,000$ words" in the model essays and make suggestions for additional changes in vocabulary.

The third component of the SRSD instructional sequence requires teachers to review students' initial writing abilities by checking their performance on a recently composed essay. In addition, our teachers also explain both the holistic scoring rubric developed by Tennessee state officials and the resulting goals for proficient writing. Teachers explain the concept of holistic scoring and engage in brief individual conferences with each student. Students receive individual copies of the scoring rubric with up to two targeted features in need of improvement.

We encourage students to select one or two goals that will remedy the identified areas of weakness. Because the general education classes often include more than 30 students, our teachers give students an assignment to work on while they wait to have their conferences. The assigned task is to practice the first step in the planning strategy (underline what are you being asked to write about once, and underline how you will develop the essay twice) on a worksheet with 12 teacher-generated prompts.

Teachers then model how to use the PLAN and WRITE strategy by "thinking aloud" when planning and composing an essay. While modeling the planning strategy, teachers include a variety of self-instructions to show how they manage the strategy and the writing process. These include selfstatements involving problem definition (e.g., "Since I decided to put my thesis statement first, I will write it as the beginning of my introductory paragraph"), planning (e.g., "Okay, my next step is to number my ideas in an order that makes sense"), self-evaluation (e.g., "I'm off to a good start"), and coping (e.g., "I really like what I've come up with so far").

While executing the strategy, teachers first identify the essential components of a given prompt and use a brainstorming sheet or create an outline (see Figure 2) to record and organize the ideas generated. Teachers use a series of cue cards to guide himself or herself through the process of translating ideas from the written plan to the essay, and an "essay sheet" (see Figure 3) to write using the correct form (indented paragraphs, and so on). We give each student a copy of the same cue cards to remind them to use main ideas from their brainstorming sheet as topic sentences for body paragraphs, to help them write basic and advanced introductory paragraphs, and to suggest appropriate transition words for introducing, connecting, and summarizing ideas.

Throughout modeling, teachers also highlight the recursive use of various processes and procedures. For example, during steps 2 and 3, "List main ideas " and "Add supporting details," teachers intentionally generate four main ideas and then select three ideas from the total pool. Similarly, during steps 8 and 9, "Try to use different kinds of sentences" and "Exciting, interesting, \$100,00 words," teachers model how to make on-line revisions when composing the essay.

Modeling is followed by collaborative practice, in which students work as a group to plan and compose an essay. Teachers with whom I have worked have approached this phase in different ways. One teacher engaged her class in two whole-class collaborative practices before starting the next stage of instruction. Another teacher chose to place students into pairs or groups of three students to complete their second collaborative essay. A third teacher organized her class into cooperative learning groups of six and assigned each student a different role for planning and composing his or her group essay.

During the final stage of instruction, independent practice, students use the strategy to write essays on their own but receive needed assistance from the teacher in applying it. Throughout this stage the teacher's goal is to reduce his or her assistance, thereby shifting responsibility for using the strategy to the student. Prompting and guidance, use of brainstorming, essay sheets, and cue cards, feedback, and so forth must be faded systematically.

At this time, students learn to assume the additional responsibility of developing essay plans and subsequent compositions on regular sheets of notebook paper. In our experience, students require approximately 5 days of independent practice (typically writing four essays). Our criterion for independent performance is for students to (a) use the strategy without relying on brainstorming, essay sheets, or cue cards, (b) generate essay within 35 minutes, and (c) demonstrate mastery of at least one self-selected goal.

Throughout the 4-week instructional cycle, students regularly use brief amounts of time to verbally rehearse the steps for PLAN and WRITE (memorization of the strategy). Teachers may give periodic, whole-class review on the mnemonics and their steps or assign students to small-group review. In addition, during or after independent practice, each teacher engages the students in a formal assessment of their learning. Teachers ask a series of written questions 


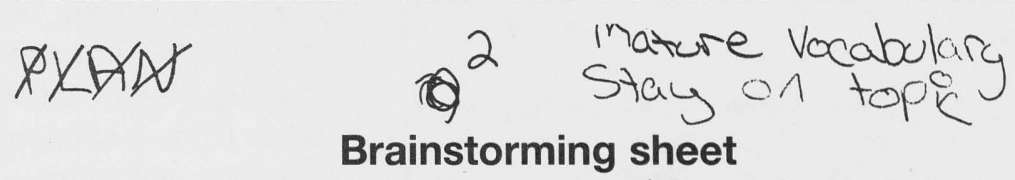

(a) possible answers to the prompt: No Schoml Start for
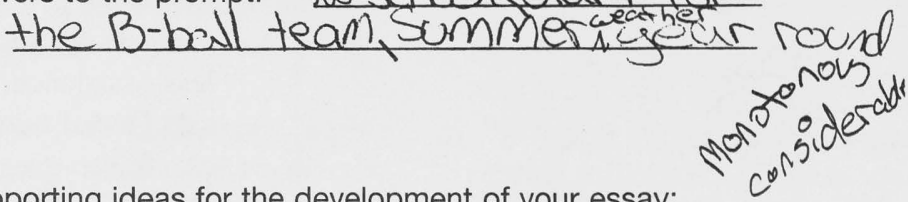

(b) main and supporting ideas for the development of your essay:
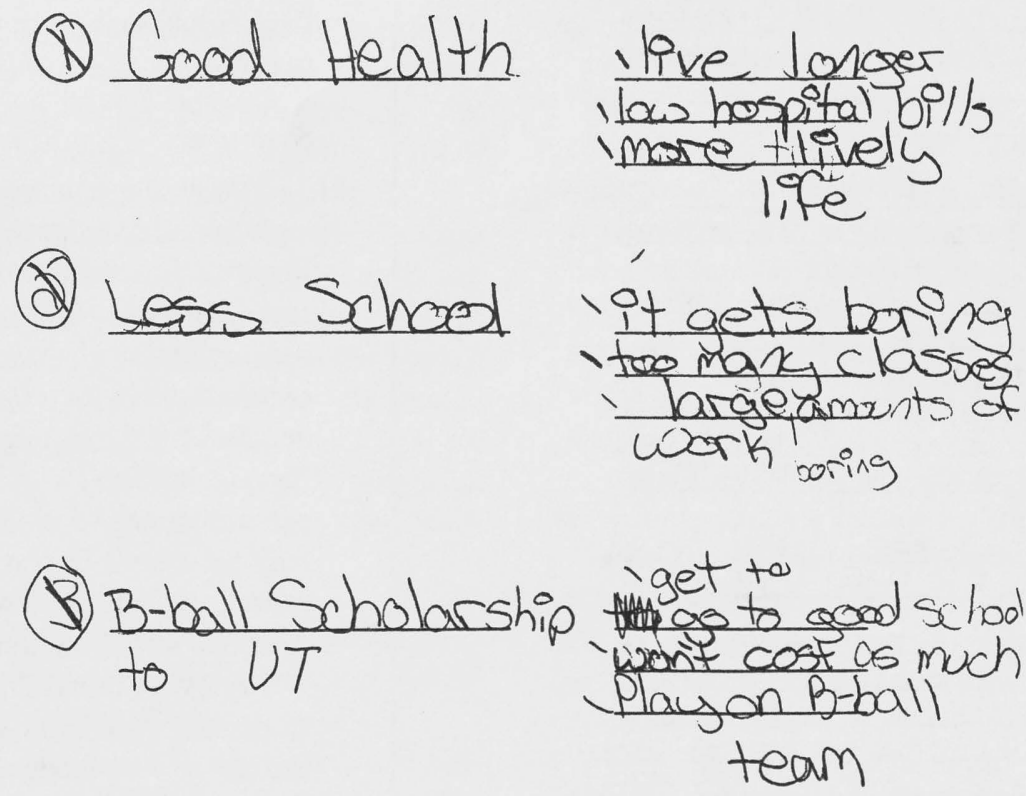

FIGURE 2

Sample plan

requiring students to recall each step of the strategy, to give examples of transition words, to provide an example of one word and an appropriate synonym, and to state how he or she plans to write an introductory paragraph. We also ask students to tell which part of the strategy they like most, and to note one self-instructional statement they use when executing the strategy.

\section{Suggestions for Promoting Student Independence}

My experience suggests that transferring responsibility to students is extremely difficult in large general education classrooms, even with adequate support from a resource teacher. Two suggestions for achieving this transition are:

1. Allow students less and less time for planning and writing as they complete each successive independent essay.
2. Remove procedural supports systematically as students become proficient in executing the strategy.

To illustrate, when students attempt their first independent composition, we allow them to set goals and to plan and compose one essay with ample teacher help and feedback in two class periods. Although students continue to receive the same amount of procedural assistance (teacher prompting and feedback and strategy materials) as they attempt their second essay, they are prompted to do so within one class period.

As students compose their third essay, they continue to use cue cards, but they then must use lined paper to create a plan and write their essay, rather than using brainstorming or essay sheets.

On the fourth, and final, practice essay, students are asked to set goals and to plan and compose an essay without 


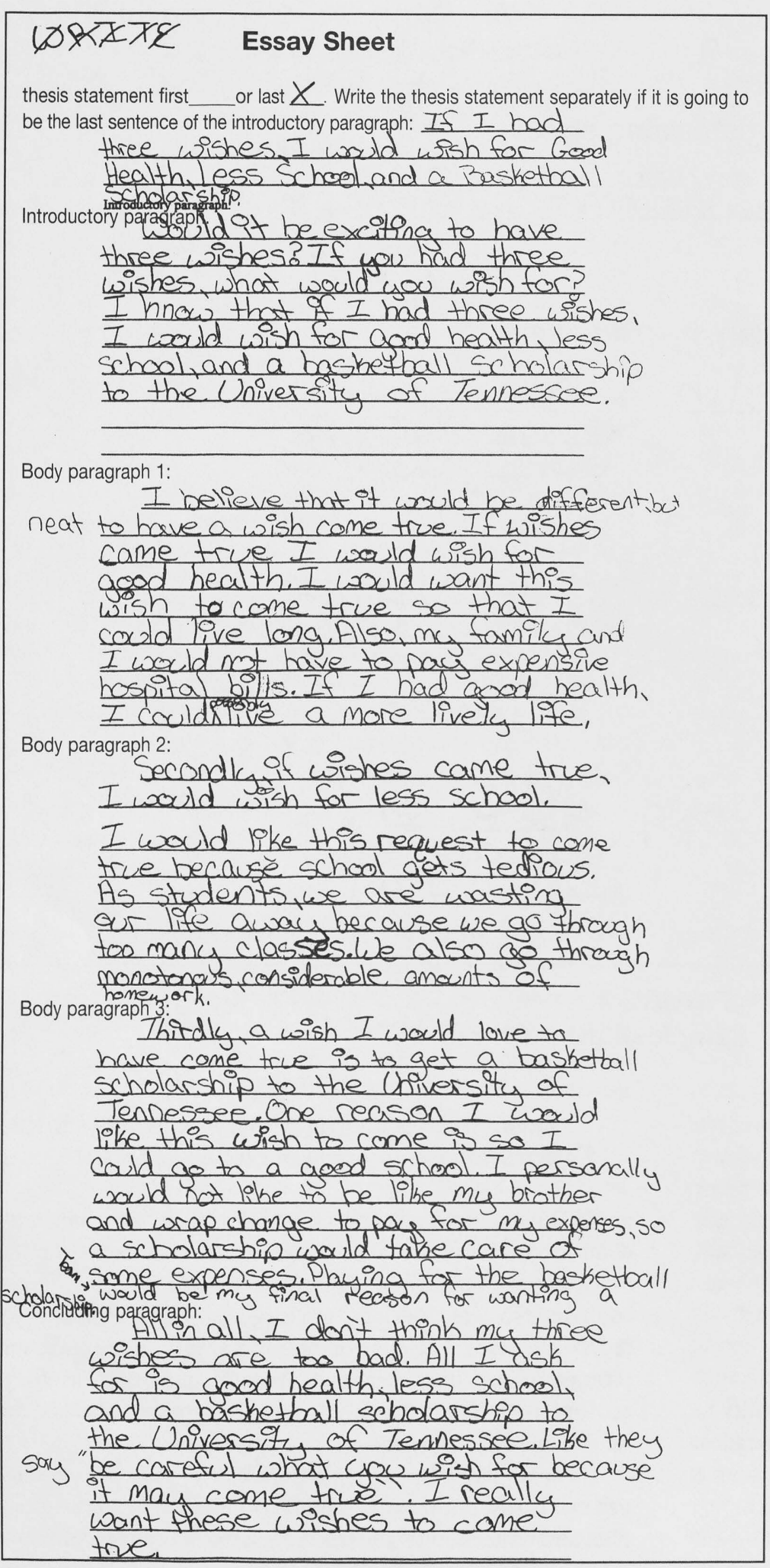

FIGURE 3

Sample essay cue cards or other materials within a single class period. Throughout the independent practice period, teachers continue to prompt students to do steps they forget, and they give feedback (or have peers give feedback) for setting new goals. At the same time, however, teachers try to provide students with less and less assistance. One remedy for students who ask for help continuously is to allow them to ask fewer questions each day (noted by tally marks on their papers so we can keep track of their questions) during the final three practice sessions.

\section{Synopsis}

This strategy proved useful for seventh- and eighth-grade students with and without learning disabilities in two middle schools in the southeastern United States who were preparing for a statewide writing assessment that required them to compose a first draft "on demand." This strategy may not prove useful for all students, nor should it be used as a generic strategy for all writing tasks. Rather, it may be useful, in part or after further modification, with students who are in need of assistance for similar writing tasks.

My own observation is that it is critical for students to set daily goals and receive either teacher or peer feedback on the quality, of their plans and essays as they learn to use the strategy independently. Experienced teachers may not be surprised that the best way to ensure student success is to circulate among students as they work, and to provide assistance only when a student skips a step or does it incorrectly.

Because the PLAN and WRITE strategy focuses almost exclusively on composing an initial draft, students also may benefit from learning to follow a series of specific procedures aimed at revising first drafts. I present next a procedural routine designed to help middle school students manage and coordinate individual revising elements.

\section{REVISING AND STUDENTS WITH LEARNING DISABILITIES}

Most models for revising (Beach \& Eaton, 1984; Bridwell, 1980; Hayes \& Flower, 1986) suggest that, for proficient writers, specific cues, such as a mismatch between intentions 
and the resulting text, trigger the process of revising. The problem then is diagnosed (although this is not obligatory), and the type of change needed is determined and carried out. As British poet, playwright, and critic Stephen Spender noted, "If you put a poem aside, when you look at it again, it tends to rewrite itself, because your remembered intention criticizes the failures of expression" (Plimpton, 1989, p.131).

Young and novice writers apparently hold a greatly simplified view of revising as they do not revise frequently, extensively, or skillfully (McCutchen, 1995). Most of the revisions they make involve superficial changes, consisting mostly of mechanical changes and word substitutions (Butterfield, Hacker, \& Plumb, 1994). Not surprisingly, this approach to revising rarely improves the overall quality of their text (Bracewell, Scardamalia, \& Bereiter, 1987).

Why do young writers have difficulty revising? There appears to be increasing support (De La Paz, Swanson, \& Graham, 1998; Graham, 1997; Scardamalia and Bereiter, 1983 ; 1985) that at least one powerful reason for such a restricted approach is that these writers have a limited capacity to coordinate and manage elements underlying the revising process. At least two approaches may be helpful in reducing this problem of executive control (Scardamalia \& Bereiter, 1986).

1. Teachers can help students make substantive revisions through the questions they ask during writing conferences (cf., Calkins, 1986).

2. Teachers can provide students with executive routines that sequentially evaluate and coordinate the revising process (Graham, 1997; Scardamalia \& Bereiter 1983, 1985).

Prior to describing our procedural routine (De La Paz, Swanson, \& Graham, 1998), teachers may wish to discuss with students potential benefits for learning how to revise. Further, students frequently need to learn that good writers routinely revise their stories and essays often doing so more than once! Revising allows students to rethink what they are trying to communicate, and to try to determine whether the reader can understand their ideas. As Elizabeth Hardwick, an accomplished American novelist, once remarked:

\footnotetext{
"It's one of the things writing students don't understand. They write a first draft and are quite disappointed, or often should be disappointed. They don't understand that they have merely begun, and that they may be merely beginning even in the second or third draft. (italics in original, Plimpton, 1989, p. 111)
}

Next, it may be helpful to activate students' prior knowledge about basic revising elements such as adding, deleting, moving, and rewriting text using procedures such as those recommended by Fitzgerald and Markham (1987). Teachers may require 1 or more days to model each technique, and then engage students in both collaborative and independent practice in executing each type of revision. When making changes, teachers use statements that provide a rationale for students, stating, for example, "This essay, doesn't have enough ideas, so I need to add another idea here for my essay to make sense." Students practice making changes first on papers that previous students have written, and then by attempting the same types of changes on their own papers.

\section{CDO: A PROCEDURAL ROUTINE FOR REVISING}

Our most recent investigation (De La Paz, Swanson, \& Graham, 1998) extended earlier work by Scardamalia and Bereiter $(1983,1985)$ and Graham (1997), in which students were taught a procedural routine that signaled movement from one element of revising to the next and that limited the number of evaluative and tactical decisions. The routine, based on Scardamalia and Bereiter's (1985) model, guides students to first compare text with an intended meaning and select a possible evaluation (e.g., "This doesn't sound right") for each chosen section of text.

They then diagnose their problems by explaining orally how the evaluation applies, and finally select a directive (e.g., "Say more") to execute, or operate on each sentence. This basic compare/diagnose/operate (CDO) procedure has been shown to prompt students to make more revisions and often results in better revisions (ones that focus on higher-level concerns).

From our findings, $90 \%$ of the students indicated the $\mathrm{CDO}$ made the process of revising easier. Moreover, CDO had a greater impact than normal revising on the overall quality of students' text. In its entirety, the CDO procedure reduced problems with executive control when revising, allowing students with learning disabilities to carry out more successful revisions.

In our study, a graduate student in special education individually taught eighth-grade students with learning disabilities to complete two revising cycles, focusing on both local and global text problems. During the first revising cycle, students learn to re-read their paper and use four evaluation cards (e.g., "Too few ideas") to identify problems related to the overall representation or structure of their text. They then select one of four tactical directives (e.g., "Add") for each selected evaluation and execute the specified revision. During the second revising cycle, they focus more attention on local concerns, as students highlight parts of their paper that still need work and select one of six evaluations (e.g., "This is a weak idea") as well as a tactical directive (e.g., "Rewrite") for each trouble spot.

We model the revising procedure in one class period, and after this brief overview, we ask students to follow the 
procedural routine when revising a previously composed persuasive essay. Teachers who plan to use the same procedural routine are likely to need additional time for students to engage in collaborative and independent practice, as well as to provide review of the CDO steps to ensure memorization of the basic procedures.

Table 2 presents an overview of the CDO procedural routine. We recommend that teachers give students a card showing the basic steps involved in using the CDO procedure. In the first step, the Compare and Diagnose phase of the CDO procedure is completed, as students first read their entire essay and select any of four evaluations, contained on $4 \times 6$ red index cards that are applicable to their paper. The four red cards contain the following evaluations: (a) Ignores obvious point against my ideas; (b) Too few ideas; (c) Part of the essay doesn't belong with the rest; and (d) Part of the essay is not in the right order.

The second step triggers the Operation phase of the procedure. Students select one of four directives, each involving a possible tactic to employ when making a needed revision, in turn, for each of the evaluations picked during the first step. Each directive is printed on a $4 \times 6$ green index card, and includes the four most common type of revisions: (a) add, (b) rewrite, (c) delete, and (d) move. During the third step, the student executes the directive selected during step 2 , and then repeats steps 2 and 3 for any remaining evaluations chosen during step 1.

The last two steps of the CDO procedure initiate the second revising cycle. During the fourth step, students re-read their paper, highlighting with a yellow marker any areas that still require changes. This step corresponds to the Compare phase of the CDO procedure. The Diagnose and Operate phases are contained in the fifth step. For each place that is highlighted, students select one of six evaluations contained on $4 \times 6$ yellow index cards and one of the four directives on the green index cards described above. The six yellow cards contain the evaluations given in Table 2. Teachers may use index cards of other colors (or plain ones) when teaching the

\section{TABLE 2}

\section{The CDO Procedure}

\section{REVISING CYCLE}

Global Concerns

Local Concerns

\section{STEPS AND OPERATIONS}

1. Compare and Diagnose:

Read essay and select red evaluation cards

2. Operation:

Select a green tactic card for each evaluation

3. Operation:

Execute tactic cards

4. Compare:

Re-read paper and highlight problems

\section{Diagnose and Operate:}

Select yellow evaluation card for each highlighted problem, a green tactic card for each evaluation, and execute tactic cards

\section{CARDS}

Red evaluation cards:

(a) Ignores the obvious point against my idea

(b) Too few ideas

(c) Part of the essay doesn't belong with the rest

(d) Part of the essay is not in the right order

Green tactic cards:
(a) Add
(b) Rewrite
(c) Delete
(d) Move

Yellow evaluation cards:

(a) This one doesn't sound right

(b) This is not what I intended to say

(c) This is an incomplete idea

(d) This is a weak idea

(e) This part is not clear

(f) The problem is 
procedural routine; however, the colors red, green, and yellow help create a "stoplight" analogy in which students first "stop" to decide what is wrong with their text, then use green tactic cards to indicate what they are "go"-ing to do to fix the problems. The second revising cycle uses yellow cue cards to indicate that students should still use "caution" in examining their text.

We recommend that teachers use as many evaluation cards as feasible when modeling the procedural routine, and that a sample essay be drafted with several problems common to students' papers. For instance, teachers may wish to use the red evaluation card, "Too few ideas," during the first revising cycle, as students with writing and learning difficulties often produce papers that are inordinately short and impoverished in detail (Graham, 1990; Thomas, Englert, \& Gregg, 1987).

While modeling the second revising cycle (steps 4 and 5), all six of the yellow evaluation cards are used once, and the open-ended evaluation (The problem is __) is applied twice to demonstrate use of this evaluation with more than one type of problem. All four green cards are used at least once in each revising cycle. The processes of comparing, diagnosing, and operating can be made more visible by thinking aloud and demonstrating how to use evaluations and tactical choices as an aid to thinking and revising. When making either an evaluative or tactical decision, teachers shuffle the appropriate set of cards to change the order each time the cards are examined, thereby reducing the likelihood that students will learn to select the same evaluative or tactical decision for each portion of text. Finally, we also find it helpful to tell students not to worry about correcting errors involving spelling, punctuation, and capitalization when using the $\mathrm{CDO}$ procedural routine. Instead, students revise first for substance, then spend additional time to correct errors in form.

\section{CONCLUDING REMARKS}

As indicated earlier, students with learning disabilities, as compared to their normally achieving peers, frequently have difficulties with written language production to a far greater extent and seem to have less knowledge about the writing process. The SRSD approach to writing instruction addresses many of these problems by explicitly teaching students to use self-regulatory procedures modeled from strategies that mature writers use to help students manage the writing process and achieve better writing products. Students with learning disabilities, however, might not use well-taught and well-learned strategies regularly and effectively (Graham, Harris \& Troia, 1998). Students may decide not to use strategies, or they may make a strategy less effective in their attempt to simplify or shorten some of its steps.
Teachers also must monitor students' approach to the writing process to ensure that they continue to use the strategies over time, and to help them adapt their use to new situations (Graham, Harris, MacArthur, \& Schwartz, 1998).

Students with learning disabilities are especially likely to need explicit instruction in comparing previously accomplished strategies and writing tasks to new ones, and they may need "booster" sessions to promote continued or adaptive use of strategies (De La Paz, 1997; Graham \& Harris, 1989). Furthermore, though the SRSD approach to writing instruction can be a powerful tool for improving the writing performance of students with learning disabilities, it is most effective when viewed within a broader context of literacy instruction. At least three other aspects of writing instruction are important to consider.

First, students, especially those with learning disabilities, typically need instruction that focuses on text production skills (e.g., spelling and handwriting), and on the conventions of English (e.g., grammar, punctuation, and various sentence forms and uses). The authors of the new NCTE/IRA English content standards support teaching students language structure and conventions. Teachers are encouraged to include direct, explicit instruction and practice of problematic aspects of language structure and also to expand students' repertoire of syntactic and lexical styles. As an alternative, use of computer applications such as word processing, speech recognition systems, and speech synthesis (De La Paz, in press b) may help students with learning disabilities circumvent problems in text production. These tools, however, continue to have a variety of limitations that may limit their effectiveness.

Second, the 1996 NAEP report on trends in academic performance notes that mainstream writing instructional approaches and emphases have evolved over time to recognize that writing is a recursive process (Campbell, Voelkl, \& Donahue, 1997). Today, language arts teachers commonly provide students with knowledge about the process of writing, and students are more likely to engage in writing for different audiences and purposes in a variety of subject areas. Moreover, the process approach to writing is believed to help students connect the study of skills such as grammar, punctuation, and spelling to wider purposes of written communication and to help incorporate those skills into their working knowledge.

In fact, proponents of the SRSD approach to writing instruction have long advocated that strategy instruction be part of students' overall writing program rather than a curricular option in and of itself (Graham, Harris, \& Troia, 1998; Pressley, et al, 1995). Investigations incorporating strategy instruction within a process approach to writing have had successful outcomes for students with and without learning disabilities (Danoff, Harris, \& Graham, 1993; 
MacArthur et al., 1996; Sexton, Harris, \& Graham, 1998). Thus, embedding direct instruction in language structure and conventions and strategy instruction within a process approach is likely to be more effective than teaching any of the same skills in isolation.

Finally, despite its obvious advantages, teachers may wonder how to accomplish SRSD instruction with large, heterogeneous groups of students, particularly in general education classrooms. Suggestions that seem to have been beneficial for several teachers with whom I have worked are as follows.

First, teachers should teach relevant content information as part of the target writing strategy. In the PLAN and WRITE strategy, for example, students are taught basic parts of an essay, different types of sentences, synonyms, and noun-verb agreement. In addition, the CDO procedural routine is most helpful for students who can already perform basic revising elements (add, delete, move, and rewrite). Teachers can accomplish instruction in needed skills simultaneously with strategy instruction.

Second, teachers should teach strategies that are relevant to their curriculum. Middle school students in Tennessee, for example, are required to participate in a writing proficiency test that focuses on expository writing. By comparison, older students in the same state must demonstrate proficiency in persuasive writing, whereas students in other states such as Oregon are required to demonstrate writing proficiency in a variety of genres (Hill, 1998). Teachers can borrow from existing, published strategies, or work with students to create their own strategies, given the task or setting demands (Collins, 1998; Harris \& Graham, 1996).

Third, as with the writing process more generally, teachers should not feel compelled to read every draft or paper that each student writes, nor should they try to give students feedback about every aspect of their writing. A more productive approach to managing this process is to create criteria for judging selected features such as content, organization, or clarity, and to give students selected feedback about their writing at various points in time. As an alternative, students give each other comments using similar rating criteria, and teachers systematically monitor selected students' responses to monitor quality of peer feedback. Another option is to incorporate subroutines or steps within a complex strategy as homework. Thus, students may be asked to explain a mnemonic and rationale for each step, or be asked to compose an introductory paragraph from a previously completed plan rather than complete an entire composition.

Finally, one teacher with whom I have worked decided to stagger her strategy instruction across an entire semester for her five language arts classes, teaching two or three classes a certain strategy and maintaining a traditional language arts focus for her remaining classes. This teacher feels she does not get tired of presenting the same content to each of her students throughout the day, and she has fewer papers to read when giving feedback to students about their progress.

Strategy instruction, and the SRSD approach in particular, makes several demands on teachers and students as they learn better approaches to composing. As with any complex form of instruction, teachers more readily become expert developers and users of strategy instruction when they receive support for their efforts and when they are able to communicate or collaborate with colleagues. The benefits of using this approach to instruction include the recognition that it is appropriate for many emerging writers, beyond those identified as having learning disabilities. Finally, students and teachers alike are enthusiastic about the SRSD approach to writing instruction as it informs both groups about "tricks" of good teaching and how to successfully manage specific components of the writing process.

\section{REFERENCES}

Anderson, P. L. (1982). A preliminary study of syntax in the written expression of learning disabled children. Journal of Learning Disabilities, 15, 359-362.

Beach, R., \& Eaton, S. (1984). Factors influencing self-assessing and revising by college freshmen. In R. Beach \& Bridwell (Eds.), New directions in composition research (pp. 149-170). New York: Guilford Press.

Bereiter, C., \& Scardamalia, M. (1982). From conversation to composition: The role of instruction in a developmental process. In R. Glaser (Ed.), Advances in instructional psychology (Vol. 2. pp. 1-64). Hillsdale, NJ: Erlbaum.

Bracewell, R., Scardamalia, M., \& Bereiter, C. (1987). The development of audience awareness in writing. (ERIC Document Reproduction Service No. ED 154 433).

Bridwell, L. (1980). Revising strategies in twelfth grade students' transactional writing. Research in the Teaching of English, 14, 197-222.

Butterfield, E., Hacker, D., \& Plumb, C. (1994). Environmental, cognitive and metacognitive influences on text revision. In E. Butterfield (Ed.), Children's writing: Toward a process theory of the development of skilled writing (pp. 83-141). Greenwich, CT: JAI.

Calkins, L. M. (1986). The art of teaching writing. Portsmouth, NH: Heinemann.

Campbell, J. R., Voelkl, K. E., \& Donahue, P. L. (1997). NAEP 1996 trends in academic progress. Washington, DC: National Center for Education Statistics.

Collins, J. L. (1998). Strategies for struggling writers. New York: Guilford.

Danoff, B., Harris, K. R., \& Graham, S. (1993). Incorporating strategy instruction within the writing process in the regular classroom: Effects on the writing of students with and without learning disabilities. Journal of Reading Behavior, 25, 295-322.

Deno, S., Marston, D., \& Mirkin, P. (1982). Valid measurement procedures for continuous evaluation of written expression. Exceptional Children, 48, 368-371.

De La Paz, S. (in press a). Self-regulated strategy instruction in regular education settings: Improving outcomes for students with and without learning disabilities. Learning Disabilities Research and Practice.

De La Paz, S. (in press b). Composing via dictation and speech recognition systems: Compensatory technology for students with learning disabilities. Learning Disability Quarterly.

De La Paz, S. (1997). Strategy instruction in planning: Teaching students with learning and writing disabilities to compose persuasive and expository essays. Learning Disability Quarterly, 20, 227-248. 
De La Paz, S., \& Graham, S. (1997a). Strategy instruction in planning: Effects on the writing performance and behavior of students with learning difficulties. Exceptional Children, 63, 167-181.

De La Paz, S., \& Graham, S. (1997b). Effects of dictation and advanced planning instruction on the composing of students with writing and learning problems. Journal of Educational Psychology, 89, 203-222.

De La Paz, S., Swanson, P. N., \& Graham, S. (1998). The contribution of executive control to the revising of students with writing and learning difficulties. Journal of Educational Psychology, 90, 448-460.

Deshler, D. D., \& Schumaker, J. B. (1986). Learning Strategies: An instructional alternative for low-achieving adolescents. Exceptional Children, $52,583-590$.

Englert, C., \& Raphael, T. (1988). Constructing well-formed prose: Process, structure and metacognitive knowledge. Exceptional Children, 54, 513-520.

Englert, C., Raphael, T., Anderson, L., Anthony, H., Stevens, D., \& Fear, K (1991). Making writing strategies and self-talk visible: Cognitive strategy instruction in writing in regular and special education classrooms. American Educational Research Journal, 28, 337-373.

Fitzgerald, J., \& Markham, L. (1987). Teaching children about revision in writing. Cognition \& Instruction, 4, 3-24.

Flower, L., \& Hayes, J. (1980). The dynamics of composing: Making plans and juggling constraints. In L. Gregg \& E. Steinberg (Eds.), Cognitive processes in writing (pp. 31-50). Hillsdale, NJ: Lawrence Erlbaum.

Graham, S. (1982). Written composition research and practice: A unified approach. Focus on Exceptional Children, 14, 1-16.

Graham, S. (1990). The role of production factors in learning disabled students' compositions. Journal of Educational Psychology, 82, 781-791.

Graham, S. (1997). Executive control in the revising of students with learning and writing difficulties. Journal of Educational Psychology, 89, 223-234.

Graham, S., \& Harris K. R. (1989). A components analysis of cognitive strategy instruction: Effects on learning disabled students' compositions and self-efficacy. Journal of Educational Psychology, 81, 353-361.

Graham, S., \& MacArthur, C. (1988). Improving learning disabled students' skills at revising essays produced on a word processor: Selfinstructional strategy training. Journal of Special Education, 22, $133-152$.

Graham, S., Harris, K., MacArthur, C., \& Schwartz, S. (1991). Writing and writing instruction with students with learning disabilities: A review of a program of research. Learning Disability Quarterly, 14, 89-114.

Graham, S., Harris, K., MacArthur, C., \& Schwartz, S. (1998). Writing instruction. In B. L. Y. Wong (Ed.), Learning about learning disabilities (2nd Ed. pp. 391-423). Orlando: Academic Press.

Graham, S., Harris, K., \& Troia, G. (1998). Writing and self-regulation: Cases from the self-regulated strategy development model. In D. Schunk \& B. Zimmerman, (Eds.), Developing self-regulated learners: From teaching to self-reflective practices (pp. 20-41). New York: Guilford.

Graham, S., MacArthur, C., \& Schwartz, S. (1995). Effects of goal setting and procedural facilitation on the revising behavior and writing performance of students with writing and learning problems. Journal of Educational Psychology, 87, 230-240.

Graham, S., MacArthur, C., Schwartz, S., \& Page-Voth, T. (1992). Improving the compositions of students with learning disabilities using a strategy involving product and process goal setting. Exceptional Children, $58,322-334$.

Graham, S., \& Weintraub, N. (1996). A review of handwriting research: Progress and prospects from 1980 to 1994. Educational Psychology Review, 8, 7-87.

Harris, K. R., \& Graham, S. (1985). Improving learning disabled students composition skills: Self control strategy training. Learning Disability Quarterly, 19, 179-200.
Harris, K. R., \& Graham, S. (1996). Making the writing process work: Strategies for composition and self-regulation. Cambridge, MA: Brookline.

Hayes, J., \& Flower, L. (1986). Writing research and the writer. American Psychologist, 41, 1106-1113.

Hill, B. (1998, February). Oregon statewide writing assessment: Results, analysis, and sample student writings. Salem, Oregon: Department of Education, Office of Assessment and Evaluation.

MacArthur, C., Schwartz, S. \& Graham, S. (1991). Effects of a reciprocal peer revision strategy in special education classrooms. Learning Disabilities Research \& Practice, 6, 201-210.

MacArthur, C., Schwartz, S., Graham, S., Molloy, D., \& Harris, K. (1996). Integration of strategy instruction into a whole language classroom: A case study. Learning Disabilities Research \& Practice, 11, 168-176.

McCutchen, D. (1995). Cognitive processes in children's writing: Developmental and individual differences. Issues in Education: Contributions from Educational Psychology, 1, 123-160.

McCutchen, D. (1988). "Functional automaticity" in children's writing: A problem of metacognitive control. Written Communication, 5, 306-324.

Montague, M., Graves, A., \& Leavell, A. (1991). Planning, procedural facilitation, and narrative composition of junior high students with learning disabilities. Learning Disabilities Research \& Practice, 6, 219-224.

Moran, M. R. (1981). Performance of learning disabled and low achieving secondary students on formal features of a paragraph-writing task. Learning Disability Quarterly, 4, 271-280.

National Council of Teachers of English and International Reading Association. (1996). Standards for the English language arts. Urbana, IL: Author.

Newcomer, P. L., \& Barenbaum, E. M. (1991). The written composing ability of children with learning disabilities: A review of the literature from 1980 to 1990. Journal of Learning Disabilities, 24, 578-593.

Newcomer, P. L., Barenbaum, E. M., \& Nodine, B. F. (1988). Comparison of the story production of LD, normally achieving, and low-achieving children under two modes of production. Learning Disability Quarterly, 11, 82-96.

Poplin, M., Gray, R., Larsen, S., Banikowski, A., \& Mehring, T. (1980). A comparison of components of written expression abilities in learning disabled and non-learning disabled children at three grade levels. Learning Disability Quarterly, 3, 46-53.

Plimpton, G. (1989). The writer's chapbook. New York: Viking.

Pressley, M., Woloshyn, V., Burkell, J., Cariglia-Bull, T., Lysynchuk, L., McGoldrick, J. A., Schneider, B., Snyder, B., \& Symons, S. (1995). Cognitive strategy instruction that really improves children's academic performance (2d ed.). Cambridge, MA: Brookline Books.

Rhoades, R. (1995). How to write. New York: William Morrow \& Company.

Sawyer, R., Graham, S., \& Harris, K. R. (1992). Direct teaching, strategy instruction, and strategy instruction with explicit self-regulation: Effects on learning disabled students' compositions and self-efficacy. Journal of Educational Psychology, 84, 340-352.

Scardamalia, M., \& Bereiter, C. (1983). The development of evaluative, diagnostic and remedial capabilities in children's composing. In M. Martlew (Ed.), The psychology of written language: Development and educational perspectives (pp. 67-95). London: John Wiley.

Scardamalia, M., \& Bereiter, C. (1985). Development of dialectical processes in composition. In D. Olson, N. Torrance, and A. Hildyard (Eds.), Literacy, language, and learning: The nature and consequences of reading and writing (pp. 307-329). Cambridge, UK: Cambridge University Press.

Scardamalia, M., \& Bereiter, C. (1986). Research on written composition. In M. Wittrock (Ed.), Handbook of research on teaching, (3d. ed., pp. 778-803). New York: Macmillan.

Scardamalia, M., \& Bereiter, C. (1987). Knowledge telling and knowledge transforming in written expression. In S. Rosenberg (Ed.), Advances in applied psycholinguistics (pp. 143-175). Cambridge, UK: Cambridge University Press. 
Schumaker, J. B., \& Deshler, D. D. (1992). Validation of learning strategy interventions for students with LD: Results of a programmatic research effort. In B. Y. L. Wong (Ed.), Contemporary intervention research in learning disabilities: An international perspective (pp. 22-46). New York: Springer-Verlag.

Sexton, M., Harris, K. R., \& Graham, S. (1998). The effects of self-regulated strategy development on essay writing, self-efficacy, and attributions of students with LD in an inclusive setting. Exceptional Children, 64, 295-311.

Swanson, H. L., \& Hoskyn, M. (1998). Experimental intervention research on students with learning disabilities: A meta-analysis of treatment outcomes. Review of Educational Research, 68 (3), 276-321.

Thomas, C., Englert, C., \& Gregg, S. (1987). An analysis of errors and strategies in the expository writing of learning disabled students. Remedial \& Special Education, 8, 21-30.
Wong, B. Y. L. (1997). Research on genre-specific strategies in enhancing writing in adolescents with learning disabilities. Learning Disability Quarterly, 20, 140-159.

Wong, B. Y. L., Butler, D. L., Ficzere, S. A., \& Kuperis, S. (1997). Teaching adolescents with learning disabilities and low achievers to plan, write, and revise compare-and-contrast essays. Learning Disabilities Research \& Practice, 12, 2-15.

Wong, B. Y. L., Wong, R., \& Blenkinsop, J. (1989). Cognitive and metacognitive aspects of learning disabled adolescents' composing problems. Learning Disability Quarterly, 12, 300-322.

\section{PERMISSIONS AND COPYRIGHT}

All rights are reserved. No part of this publication may be reproduced, photocopied, faxed, stored in a retrieval system, or transmitted in any form or by any means, electronic, mechanical, recording or otherwise, without the prior written permission of the publisher.
Back issues are available for sale. Reproduction requires permission and payment of fees. It is illegal and a violation of federal copyright law to reproduce this publication without permission. Direct all inquiries to the permissions editor. 